\title{
Competitive Pressure: Competitive Dynamics as Reactions to Multiple Rivals
}

\author{
Leon Zucchini Tobias Kretschmer
}

Discussion Paper 2011-03

August 2011

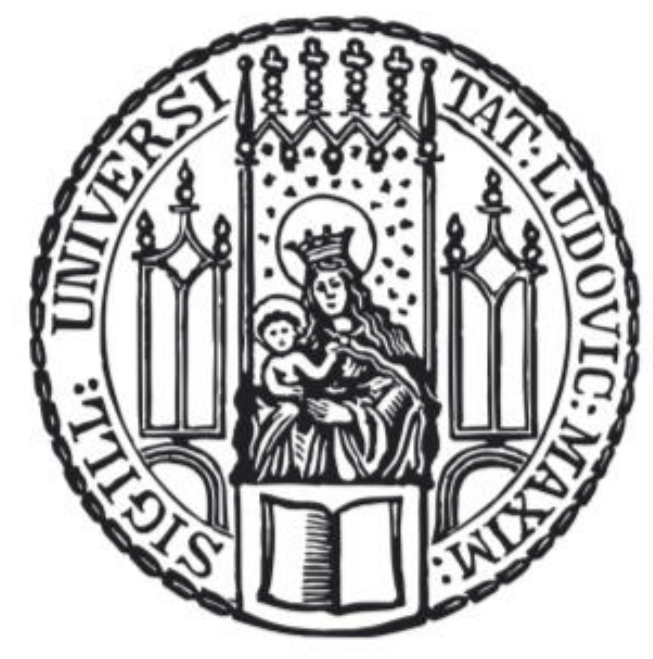

Munich School of Management University of Munich

Fakultät für Betriebswirtschaft

Ludwig-Maximilians-Universität München

Online at http://epub.ub.uni-muenchen.de 


\title{
COMPETITIVE PRESSURE: COMPETITIVE DYNAMICS AS REACTIONS TO MULTIPLE RIVALS*
}

\author{
Leon Zucchini $^{* *}$ \\ Institute for Strategy, Technology and Organization \\ Ludwig-Maximilians-University Munich \\ Schackstr. 4/III, D - 80539 Munich \\ l.zucchini@lmu.de \\ Tobias Kretschmer \\ Institute for Strategy, Technology and Organization \\ Ludwig-Maximilians-University Munich \\ Schackstr. 4/III, D - 80539 Munich \\ t.kretschmer@lmu.de
}

August 2011

\begin{abstract}
Competitive dynamics research has focused primarily on interactions between dyads of firms. Drawing on the awareness-motivation-capability framework and strategic group theory we extend this by proposing that firms' actions are influenced by perceived competitive pressure resulting from actions by several rivals. We predict that firms' action magnitude is influenced by the total number of rival actions accumulating in the market, and that this effect is moderated by strategic group membership. We test this using data on the German mobile telephony market and find them supported: the magnitude of firm's actions is influenced by a buildup of actions by multiple rivals, and firms react more strongly to strategically similar rivals.
\end{abstract}

Keywords: Competitive rivalry, competitive dynamics, strategic groups, mobile telecommunications.

*We gratefully acknowledge comments by Peter Bryant, Christoph Dehne, JP Eggers, Alex Oettl, Nils Stieglitz, Catherine Tucker, Joachim Winter, Walter Zucchini and audiences at the AOM Meetings 2011, DRUID Annual Conference 2011, TIME Colloquium Munich, EBS Business School, Freie Universität Berlin, and the University of Southern Denmark. Any remaining errors are our own.

** Corresponding author. 


\section{INTRODUCTION}

Deutsche Telekom's price cuts were a reaction to the price decline in the German market for mobile telephony. - Handelsblatt 12/2005

In many industries firms constantly have to defend themselves against rival attacks on their competitive position (Smith et al., 1991, 2001). In turn, their actions may provoke retaliation from their rivals, further fuelling competition (Chen et al., 1992; Yu and Cannella, 2007). The outcomes of competitive interactions determine competitive advantage and thus profitability (Chen and Hambrick, 1995; Ferrier, 2001), so understanding their underlying mechanisms is central to competitive analysis and strategic management research in general (Chen, 1996; Ketchen et al., 2004; Smith et al. 2001).

In the past two decades competitive dynamics research has analyzed competitive behavior between rival firms at the level of individual competitive actions (Ketchen et al., 2004; Hutzschenreuter and Israel, 2009). A central question in this research is which factors induce firms to make competitive moves (Chen and Miller, 1994; Ferrier et al., 1999, 2002). Focusing on action-reaction dyads, i.e. matching pairs of actions and responses, scholars found evidence that firms are affected by their rivals' actions (Smith et al., 1992; Chen et al., 1992; Chen and MacMillan, 1992; Chen et al., 2007).

The action-reaction dyad is useful in providing a clear link between individual actions and responses, but it implies two strong assumptions, as first noted by Hsieh and Chen (2010): First, managers perceive actions by rival firms individually and not to evaluate them jointly. Second, each response is targeted towards an individual rival action, not towards several rivals at once. These assumptions are useful in situations with few similar rivals, but in industries with many heterogeneous players this concept of competition may be too narrow. Consequently, we ask if competitive actions by multiple rivals also jointly influence firm actions (Hsieh and Chen, 2010).

Specifically, we ask whether firms' competitive moves are influenced by the gradual buildup of actions by multiple rivals over time and if there are differences between reactions within the same strategic group and across different groups. Based on the awareness-motivation-capability (AMC) framework (Chen and Miller, 1994; Chen, 1996) we propose that as they observe an 
increasing buildup of rival moves their firms' last action managers perceive increasing 'competitive pressure', i.e. a perceived necessity to take competitive action. Drawing on work on rivalry in strategic groups we study the moderating effect of strategic group membership on their reactions to multiple rivals (Porac and Thomas, 1990, Reger and Huff, 1993; Ferrier et al., 1999; Chen and Hambrick, 1995). We propose that in managers' cognitive constructions of the competitive landscape they perceive actions by strategically similar rivals as especially salient, leading to greater competitive pressure (Porac et al., 1995, Nath and Gruca, 1997)

We address these questions by examining action magnitude as a central attribute of competitive moves (Smith et al., 1992), using data on tariff setting in the German cellular telephony market. We propose that greater competitive pressure leads to greater magnitude of firms' subsequent actions, specifically the number of tariffs introduced. ${ }^{1}$ Our empirical results support our theoretical arguments: in general, the more actions that have accumulated in the market since a firm's last competitive move, the greater that move's magnitude. We also find that the effect of rival actions on action magnitude is moderated by firm type: challengers react more strongly (even exclusively) to rival challengers' actions, and incumbents react to rival incumbents' actions. We conclude that competitive pressure and the link to rivalry in strategic groups provide a promising new perspective on competitive dynamics.

By analyzing firms' reactions to multiple rivals this study complements Hsieh and Chen (2010) in introducing a new perspective of competitive interactions. It also contributes to theory by discussing how awareness, motivation and capability influence competitive pressure, thus extending the AMC framework to rivalry between a firm and groups of competitors (Chen and Miller, 1994; Chen, 1996). Finally, it provides a further link between competitive behavior and strategic group research by demonstrating that firms react differently to rival actions from within or outside their own strategic group (Cool and Dierickx, 1993; Porac and Thomas, 1994; Porac et al., 1995; Smith et al., 1997; Leask and Parker, 2007).

\footnotetext{
${ }^{1}$ However, we neither propose nor observe a snowballing 'Red Queen' effect (Barnett and Sorenson, 2002). This is discussed below.
} 
The paper is structured as follows: we first develop our theoretical framework and derive hypotheses. We then present the data and research methods, and report our empirical results. We then draw conclusions and identify directions for future research.

\section{THEORETICAL FRAMEWORK AND HYPOTHESES}

\section{Competitive Pressure}

Competitive interaction consists of 'externally directed, specific, and observable competitive move[s] initiated by a firm to enhance its relative competitive position' (Smith et al., 2001: 321). Consequently, competitive moves are at the heart of competitive dynamics research. Scholars studied how competitive moves are shaped by characteristics of the acting firm, e.g. size and past performance, as well as by industry characteristics, e.g. buffering from competition and industrylife-cycle (Chen and MacMillan, 1992; Ferrier et al., 2002; Más-Ruiz et al., 2005; Fjeldstad et $a l .$, 2004). The main focus, however, is on inter-firm interaction, i.e. how a firm's competitive moves are driven by their rivals' behavior (Bettis and Weeks, 1987; Smith et al., 2001).

Most work on these interactions studies action-reaction dyads consisting of a matching pair: an action and a reaction in direct response (for example a firm launching a new product and a competitor responding with a price cut) and are typically identified through content analysis of third-party reports or newspapers (Chen et al., 1992; Yu and Cannella, 2007). By linking competitive actions and reactions many studies establish a clear connection between competing firms' moves and previous rival actions (Smith et al., 2001; Hutzschenreuter and Israel, 2009).

However, inherent in the main advantage of the action-reaction dyad approach - the fact that it allows a clear identification of matching pairs of competitive moves - is also a potential drawback. As pointed out by Hsieh and Chen (2010), it implies two strong assumptions about competitive interactions. First, it assumes that firms perceive each rival action individually and are unaware of (or disregard) potential interdependencies. Second, it assumes that firms' reactions are exclusively responses to individual actions by specific rivals and never to multiple actions at once. In mature industries with a small number of highly visible rivals these assumptions may hold, but in dynamic markets with a large number of firms they seem excessively restrictive. There, it seems more plausible that only some of a firm's actions are 
direct responses to an attack by an individual competitor whereas others may be directed towards several rivals at once as the firm attempts to improve its relative competitive position.

In this paper we develop an alternative perspective of competitive interaction to complement the action-reaction dyad. We propose that firms perceive the sum of all rival actions in the market jointly: as each firm observes its rivals' actions accumulate since its last competitive move it faces an increased threat of finding itself at a competitive disadvantage and consequently is increasingly motivated to react. We call the perceived necessity to act through a summary evaluation of multiple rivals' actions 'competitive pressure', going back to Porter's description of competitive interaction (1980: 17). We predict that competitive pressure influences firm behavior, i.e. that firms make competitive moves in response to 'the aggregate impact of multiple rivals' actions' (Hsieh and Chen, 2010: 3).

We use the term 'competitive pressure' to distinguish the concept from 'perceived competitive tension', defined by Chen et al. (2007: 103) as, 'the extent to which a firm's managers and industry stakeholders consider a given rival to be the focal firm's primary competitor'. As discussed by Chen et al. (2007), competitive tension is a dyad-level construct, i.e. it describes the (possibly asymmetric) perceived relationship between a pair of rival firms. In contrast, competitive pressure describes a perceived relationship between a firm and its entire competitive environment. Thus it complements the concept of competitive tension.

Ferrier and Lee (2002) compare the exchange of competitive actions between firms to fighters exchanging punches in a boxing match. To describe competitive pressure we propose a different sporting metaphor: firms are like runners in a race where each individual competes against all the others, although intermittently he or she may put in a burst of speed to improve the competitive position.

\section{Awareness-Motivation-Capability Framework}

To investigate how firms perceive competitive pressure and how it affects their actions we draw on the awareness-motivation-capability (AMC) framework. ${ }^{2}$ The AMC framework has its

\footnotetext{
${ }^{2}$ To be precise we investigate how managerial teams perceive competitive pressure. As our focus is not on micro-processes within firms we use "firm" as shorthand for the groups of managers perceiving pressure.
} 
origins in psychology and is used frequently in competitive dynamics research (Chen and MacMillan, 1992; Chen, 1996; Smith et al., 2001). It suggests that firms will respond to rivals' actions if three conditions are met: they must be aware of the moves, motivated to respond to them, and they must possess the necessary capabilities to do so.

Competitive pressure depends on a firm's awareness of rival moves and its motivation to respond to them. If a firm is unaware of rival actions it cannot perceive a need to respond, motivated though it may be (Chen and Miller, 1994). If a firm is aware of rival actions but not motivated to respond, e.g. because they are not perceived as threatening, it will also not perceive competitive pressure. However, if a firm is both aware of rival actions and motivated to respond, we propose that it will feel the need to respond, or 'competitive pressure'.

While a buildup of rival moves influences awareness and motivation, there is no immediate reason why it should influence a firm's capability to respond (at least in the short run). We therefore do not hypothesize about the influence of capability on competitive pressure.

Our argument is threefold: first, competitive pressure can arise from a firm's awareness of and motivation to respond to a buildup of actions by one or more rivals. Second, firms will seek to relieve competitive pressure by making competitive moves. Third, these moves may be directed towards several rivals at once. This argument is consistent with the finding by Hsieh and Chen (2010) that an increasing number of rival actions increases the likelihood that a firm will make a competitive move to protect its competitive position, and with Reger and Huff (1993) who show that managers' actions are influenced by perceived rivalry.

Most previous research on competitive dynamics has abstracted from reactions to multiple

rivals, focusing on action-reaction dyads (Smith et al., 2001; Hsieh and Chen, 2010). Thus, the argument made above adds to our understanding of competitive processes by describing how competitive moves by multiple rivals jointly influence a firm's action.

\section{Competitive Pressure and Action Magnitude}

We focus on one central aspect of firms' competitive moves, their magnitude. Action magnitude is interesting for two reasons: first, it provides an indication of how large a competitive impact the firm is attempting to achieve. Second, it is a proxy for how much effort and risk an action implies for a firm: large actions require more resources to implement and are 
less easily reversible (Smith et al., 1992; Chen and MacMillan, 1992). As argued above, a firm observing a buildup of rival actions since its last action will perceive increasing competitive pressure. Eventually the pressure will become so great that the firm will attempt to relieve it through a competitive move. We propose that a firm perceiving more competitive pressure will both try to make its action count for more (i.e. have more impact on its relative competitive position), and be more willing to accept greater cost and risk. This is consistent with the finding in the study by Bothner et al. (2007) that racing drivers take greater risks if their competitive position is threatened by rivals. Thus, our first hypothesis is:

\section{[H1] The greater the number of rival actions since a firm's last competitive move, the greater the magnitude of its next move.}

The proposed effects and the related constructs of awareness, motivation, and capability are illustrated in Figure 1. The moderating influence of firm type is discussed in more detail below.

An alternative mechanism to the one we propose is also conceivable: instead of reacting to rival actions directly, firms may instead be observing only their bottom line and reacting to changes there which in turn may be caused by rival actions. In our empirical setting the two mechanisms are observationally indistinct, but the data suggest this alternative explanation is highly unlikely. We observe telecommunications firms introducing tariffs every 2 to 5 months, and a bottom line effect from rival actions in such a short time would imply an extremely high degree of price elasticity. As Grzybowski and Pereira (2008) find that the German market for mobile telephony is inelastic (elasticity of -0.38 for calls), we are confident that our results are not strongly influenced by this alternative mechanism. Nevertheless, disentangling the two effects in other markets may be an interesting direction for future research.

INSERT FIGURE 1 AROUND HERE

\section{Moderating Effect of Firm Type}

Firms react to competitive moves by multiple rivals. However, not all rival moves are equal: the strength of a firm's reactions may differ for different rivals and different actions. For example, certain actions may be more visible and motivate more responses, for example those 
that particularly threaten a firm's key markets (Chen et al., 1992). Another possibility - and our focus - is that firms feel greater pressure from certain groups of rivals than from others. Indeed, there is evidence that firms perceive a different degree of rivalry towards different competitors (Porac and Thomas, 1990; Chen et al., 2007; Kilduff et al., 2010; Marcel et al., 2011).

Porter (1979) proposed that rivalry may differ between groups of competitors with similar strategies. Although the strategic group concept has been debated (Hatten and Hatten, 1987; Barney and Hoskisson, 1990; Tang and Thomas, 1992) there is evidence that strategic groups do affect rivalry. For example, Cool and Dierickx (1993) find that in the early stages of the U.S. pharmaceutical industry, firm rivalry within the same strategic group was stronger than between firms in different groups. Strategic groups have also been found to directly influence firms' competitive actions (Smith et al., 1997; Más-Ruiz et al., 2005; Fernández and Usero, 2009).

One possible reason for the effect of strategic similarity on competitive behavior is that it may shape the way managers perceive competitive rivalry (Porac and Thomas, 1990; Reger and Huff, 1993; Porac et al., 1995; Peteraf and Shanley, 1997). Reger and Huff (1993) argue that managers consciously or unconsciously group competitors to make sense of complex competitive situations, that these groups are distributed and adapted through managerial interaction and that this leads to a shared perception of 'cognitive strategic groups'. Related work by Porac and coauthors finds that firms consider others that are similar in some key attributes as close rivals and adjust their competitive behavior accordingly (Porac et al., 1989; Porac and Thomas, 1990, 1994). In particular, in one study 'large firms rivaled large firms and small firms rivaled small firms.' (Porac et al., 1995:224).

We therefore propose that the competitive pressure experienced by a firm may depend on whether the actions it observes are made by rivals within or outside its own strategic group. ${ }^{3} \mathrm{We}$ draw on strategic group theory and the awareness-motivation-capability framework to investigate exactly how group membership influences competitive pressure.

First, we propose that firms are more likely to be aware of actions by rivals in their own strategic group. This is because in complex market situations managers construct simplified

\footnotetext{
${ }^{3}$ We do not distinguish between the concepts of 'strategic' and 'competitive' groups (Leask and Parker, 2007).
} 
models of the competitive arena to make appropriate strategic decisions. Research based on cognitive and social learning theories provides significant evidence that they do so by focusing on a few similar firms (Porac et al., 1995; Peteraf and Shanley, 1997).

Strategic group membership may also affect firms' motivation to respond to rival actions for several reasons. First, social learning theory suggests that a strong strategic group identity may lead to a myopic view of competition (Peteraf and Shanley, 1997), causing firms to disregard actions by rivals from other strategic groups as they do not perceive them as threatening (Porac et al., 1995). Second, strategic group membership may influence firms' motivation to respond due to market similarity. For example, Chen (1996) argues that managers perceive competitive actions by rivals with similar markets as particularly threatening. Third, firms in the same strategic group are likely to have similar resource bases, giving them the capability to contest with rivals. Although it has been argued that this might decrease motivation (Young et al., 2000), Chen et al. (2007) find that greater capability to contest leads to a greater perception of competitive tension between pairs of firms. This is because stakeholders view them as direct competitors and also because they are likely to compete for resources, and we propose the same holds for competitive pressure. In summary, we propose that due to social group perception, greater market commonality and greater capability to contest, managers are more motivated to respond to actions by rivals from their own strategic group.

Besides being motivated, firms in the same strategic group are likely to have the necessary capability to react to each other's actions as they will tend to have similar resources, similar interpretations of the competitive landscape and possibly even overlapping identity domains (Chen, 1996; Porac and Thomas 1990; Chen et al., 2007; Livengood and Reger, 2010).

Several dimensions have been proposed (and extensively discussed) to identify strategic groups (McGee and Thomas, 1986; Ketchen and Shook, 1996). A common distinction is between incumbents and challengers in an industry (Porter, 1979; Máz-Ruiz et al., 2005; Fernández and Usero, 2009). Incumbents are typically larger, hold dominant relative market positions, and possess significant captive resources, while challengers are typically smaller and have less market power and resources (Ferrier et al., 1999). Since cognitive strategic groups correspond to groups based on archival measures like size (Nath and Gruca, 1997; Chen et al., 
2007), we propose that the argument above holds for rivalrous behavior between challengers and incumbents, and use this distinction in our empirical analysis.

Our second argument is therefore that as managers observe rival actions accumulating in the market, they experience greater competitive pressure from actions by rivals in their own strategic group (of their own type). Building on our first hypothesis that greater competitive pressure leads to greater action magnitude, this leads to our second and third hypotheses:

[H2] The magnitude of an incumbent's competitive moves is more strongly influenced by other incumbents' than by challengers' actions.

[H3] The magnitude of a challenger's competitive moves is more strongly influenced by other challengers' than by incumbents' actions.

\section{DATA AND METHODS}

\section{Data}

Our dataset covers the German market for mobile telephony during the period from June 2005 to February 2009. It contains monthly observations of all tariffs offered by all firms in the market. The data was collected by teltarif, a price-comparison website for telephone and broadband tariffs, and subjected to extensive cleaning. ${ }^{4}$

The market for mobile telephony is especially well suited for our research questions for two reasons. First, tariffs in this market constitute both the price and the product offered by the firms. In the period under consideration there were no longer significant differences in coverage or call quality between the mobile network providers in the German market. Creating tariffs was therefore one of the main means of differentiation except advertising (German Federal Network Authority, 2009:74). Miravete (2009) supports this point: he finds evidence in the US mobile telephony market that nonlinear tariffs like the ones considered here are indeed strategic complements (i.e. a means for differentiation).

\footnotetext{
${ }^{4}$ The most important data cleaning steps are described in the Appendix.
} 
Second, the industry structure in Germany during our study period allows lets us clearly identify incumbents and challengers. The incumbents in the market are the four large mobile network operators (MNOs) that entered the market the 90's and together hold approximately 85\% market share (T-Mobile, Vodafone, E-Plus and O2). The challengers are 34 small mobile virtual network operators (MVNOs) that enter the market from 2005 onwards and operate partially locally and partially at a national level. Besides the difference in entry timing and market share the incumbents and challengers also differ with regard to resources. MNOs are vertically integrated, owning and operating their own infrastructure. In contrast, MVNOs buy airtime from MNOs and use it to construct new tariffs that are sold under their own brand.

A third group of companies in the market, seventeen tariff resellers, were excluded from the analysis. They operate mainly as an independent distribution platform for MNO tariffs and a large proportion of their offering comprises MNO tariffs sold under a joint brand. Including them in the analysis would artificially inflate the number of tariffs in the market. It could also produce a spurious effect: tariff resellers routinely offer bundles of new tariffs shortly after activity by MNOs, but this is merely a result of including the new MNO tariffs in their portfolios.

Although tariffs are obviously targeted at different consumer segments, e.g. occasional callers and heavy usage business consumers, the dataset initially lacked a classification of market segments. We therefore allocate each tariff to one of four market segments (subsequently referred to as 'markets') using standardized usage baskets (German Federal Statistical Agency, 2006). The markets reflect four different consumer types: rare, low, average and heavy users. The allocation of tariffs to markets was performed with a standardized algorithm, checked by hand, and subjected to extensive robustness tests. This is described in detail in the Appendix.

\section{Variables}

We do not directly observe competitive pressure - this would require data on perception, e.g. from interviews with managers (Porac et al., 1995). In Figure 1 this is indicated by the dashed boxes. Instead, we observe three elements in the model via archival data: rival actions, firm type and the resulting competitive moves. This approach is supported by Chen et al. (2007) who find perceptual measures of competitive tension to be closely related to 'objective' archival measures. 
Our basic unit of observation is a firm's activity in each market and month. A firm is considered to have made a competitive move if at least one new tariff is introduced in a given month and market.

Action Magnitude. The dependent variable, action magnitude, is measured as the number of tariffs introduced by a firm in a given month and market. This simple measure allows us to capture the two central characteristics of action magnitude: the effort of implementation and the targeted impact for competitors. A firms' first introduction of tariffs when it enters the market is not counted, as it cannot be considered a 'reaction'. 5

Challenger Actions. The first of our two main independent variables is the number of actions by rival firms that are classified as challengers. It is measured as the number of tariffs introduced by all challengers (except the focal firm) in the market in question since the focal firm's last tariff introduction in that market. Given our focus on the buildup of competitive pressure this measure is designed as a 'stock' measure as opposed to the 'flow' measures - e.g. a moving average of rival activity - commonly found in the competitive dynamics literature (Young et al., 1996; Hsieh and Chen, 2010).

Incumbent Actions. Our second main independent variable is the number of actions by incumbent rivals. It is measured as the number of tariffs introduced by all incumbents (except the focal firm) in the market in question since the focal firm's last tariff introduction in that market (again a stock measure). We drop incumbent actions on the same network as the focal firm to adress two industry-specific concerns about the data discussed in more detail below.

Incumbent. This is a dummy variable for the firms' type, coded 1 for incumbents.

Fixed Effects. To account for the panel data structure and unobserved, time-invariant differences we include fixed-effects dummies for markets and firms. To account for seasonal effects we also include fixed-effects dummies for the months of the year.

\footnotetext{
${ }^{5}$ Results would not change qualitatively if we included these.
} 


\section{Econometric Analysis}

Our dependent variable is limited to positive integers. Therefore OLS is inappropriate as it assumes the dependent variable to be continuous and unbounded. The standard regression model for positive, discrete-valued data is a Poisson model (Greve, 2003; Keil et al., 2008; Li, 2008). However, in a standard Poisson distribution mean and variance are equal, whereas in our data the variance of action magnitude is almost four times the mean $\left(\widehat{\mu}=0.389\right.$ and $\left.s^{2}=1.478\right)$ indicating severe overdispersion. The main cause of the overdispersion is a large number of zero counts and we therefore use a zero-inflated Poisson model (Lambert, 1992; Winkelmann, 2003). Vuong tests between the two models (not reported) indicate that the zero-inflated model is a substantial improvement over the standard model. The sample size is easily large enough to warrant use of this type of model, and graphical analysis showed residuals to be approximately normally distributed, indicating that it provided an appropriate fit. Robustness tests using negative binomial, standard Poisson and OLS models are reported below.

The zero-inflated Poisson model is a nested model including a logit ('inflation') model to account for zeros in excess of what would be predicted by a normal Poisson, and conditional on that a Poisson model. We estimate the model using interaction terms and fixed-effects:

$G=\beta_{0}+\beta_{1} C A_{i j t-\tau}+\beta_{2} I A_{i j t-\tau}+\beta_{3} I n c_{i}+\beta_{4} I n c_{i} \times C A_{i j t-\tau}+\beta_{5} I n c_{i} \times I A_{i j t-\tau}+\gamma Z+\epsilon_{i j t}$

On the left hand side $G=\log (\omega /(1-\omega))$ for the inflation model, where $\omega$ is the probability of observing an excess zero. For the Poisson model $G=\log (\lambda)$, where $\lambda$ is the mean of the Poisson distribution. On the right hand side, $I A_{i j t-\tau}$ and $C A_{i j t-\tau}$ are the number of actions in market $j$ by all incumbents and challengers (respectively) except firm $i$ between the current month $t$ and month $\tau$, when firm $i$ last introduced a tariff in market $j$. $I n c_{i}$ is the dummy variable indicating firm $i$ 's type, and the interaction terms are specified by multiplying $I n c_{i}$ with the main independent variables. The interaction terms allow us to assess if the slopes of the reaction to actions by rival incumbents and challengers on a firm's action magnitude differ depending on which group the firm belongs to itself. They thus constitute a formal test of Hypotheses 2 and 3 : Hypothesis 2 predicts that the marginal effect of $I n c_{i} \times I A_{i j t-\tau}$ on action magnitude is positive, so that the effect of rival incumbents' actions is stronger if the focal firm is an incumbent. 
Hypothesis 3 posits that the marginal effect of $I n c_{i} \times C A_{i j t-\tau}$ on action magnitude is negative. $Z$ indicates fixed effects dummies, $\beta$ and $\gamma$ are regression coefficients, and $\epsilon$ is an error term.

\section{Controls for Wholesale Pricing and Corporate Policy}

We address two industry-specific issues related to the connection between challengers' action magnitude and previous actions by incumbents. They concern the potential influence on our results of wholesale prices and subsidiaries.

The concern about wholesale prices is related to the challengers' dependency on the incumbents' infrastructure. The incumbents in this market are vertically integrated: they both sell cellular telephone services and operate their own physical networks (i.e. transmission masts, fixed-line backbones and switches). In contrast, challengers do not own or operate infrastructure. Instead, they buy airtime wholesale from the incumbents and rebundle them into new tariffs. The concern is that a change in wholesale prices by an incumbent would imply a change in input prices for all the challengers operating on its network. This could make it necessary for the challengers to introduce new tariffs, and an incumbent might anticipate this change by introducing new tariffs of its own. In the data, this would appear to be an exchange of competitive actions (incumbent lowers prices, challengers react by lowering prices as well) rather than supply-side input price adjustment.

The second concern is that some of the challengers and incumbents belong to the same corporation, e.g. Base (challenger) and E-Plus (incumbent). Although the challengers are generally legally independent subsidiaries that service low-usage markets under a separate brand it is conceivable that they might be acting in concert with the relevant incumbent, thereby biasing our results. Note that challengers and incumbents belonging to the same corporation always operate on the same network.

We address these concerns by dropping previous actions by incumbents on the same network as the focal firm for the calculation of the independent variables. We thus use only tariff introductions by incumbents on a different network, ensuring that neither changes in wholesale prices nor corporation-wide policies influence our results. Note that if the focal firm is an incumbent the problems do not arise, as incumbents always operate on their own networks. 


\section{RESULTS}

\section{Main Results}

Tables 1 and 2 report descriptive statistics and correlations for the dependent and main independent variables. We observe a total of 819 tariffs offered by 38 companies in four market segments for 45 months. Overall, this results in 2,105 firm-month-market observations (note that not all firms were active in all markets in all months). The correlations between the independent variables are mild, indicating that multicollinearity is not a major concern. Further multicollinearity tests are reported below.

\section{INSERT TABLES 1 AND 2 AROUND HERE}

Table 3 reports our main regression results and marginal effects. Model (1) is a baseline model without interaction terms, Model (2) contains our main regression. The two nested models of the zero-inflated Poisson model are shown in the upper and lower parts of the table. The lower part of the table reports the logit ('inflation') model estimating the likelihood of excess zeros and the upper part of the table shows the results of a standard Poisson model. $\chi^{2}$-tests indicate that all models have explanatory power $(p=0.000)$. The coefficient estimates for the fixed- and timeeffects dummies are not reported. ${ }^{6}$

Both the logit and Poisson models are generalized linear models and the regression coefficients cannot be interpreted as marginal effects as in linear models (Norton et al., 2004; Hoetker, 2007). We calculate average marginal effects for each independent variable and report them for Models (1) and (2) in columns ME(1) and ME(2), respectively. ${ }^{7}$

\section{INSERT TABLE 3 AROUND HERE}

\footnotetext{
${ }^{6}$ Results are available from the authors.

${ }^{7}$ Using a Monte-Carlo simulation to calculate the marginal effects for our main model over a range of covariate values as suggested by Zelner (2009) yields qualitatively similar results.
} 
Hypothesis 1 [H1] predicts that action magnitude is positively related to the number of previous competitor actions. This is partially supported by the results in Table 3: the marginal effects in our main model $\mathrm{ME}(2)$ are positive and significant for challengers' actions but negative and significant for incumbents' actions. This implies that whereas a greater number of previous moves by challengers is associated with greater action magnitude, more previous moves by incumbents reduce action magnitude. This surprising result is analyzed in more detail below.

According to our second hypothesis [H2] incumbent action magnitude is more strongly influenced by previous incumbents' actions than by challengers' actions. This is supported by the marginal effects reported in $\mathrm{ME}(2)$ : the marginal effect of an increase in the interaction term between the incumbent dummy and challenger actions is negative and significant. This indicates that previous moves by challengers influence incumbents' action magnitude less strongly than they do challengers' action magnitude.

Hypothesis 3 [H3] argues that challengers are more strongly influenced by challengers' actions than incumbents' actions. This too is supported by the results in $\operatorname{ME}(2)$ : The marginal effect of the interaction between the incumbent dummy and incumbent actions is positive and significant at the $10 \%$ level. We conclude that previous moves by incumbents influence incumbents' action magnitude more strongly than challengers' action magnitude.

As more rival actions cause firms to make greater moves in response, one might expect the number of tariffs in the market to spiral upwards, suggesting a 'red queen' effect (Barnett and Sorenson, 2002). However, the marginal effects in our models are all well below one, so the effect of additional moves on action magnitude is rapidly dampened. This is consistent with the overall pattern in the data, as the average number of tariffs introduced per firm-market-month is approximately constant from 2006 through 2009 (averages of 0.9440 and 1.141 respectively).

\section{Split Samples}

Although our first hypothesis is partially supported - previous challenger actions are associated with larger action magnitude - the negative marginal effect of incumbent actions on action magnitude runs contrary to expectations. To further analyze this result we split our data into two subsets that are analyzed separately: one includes only incumbents' reactions, the other 
only challengers' reactions as dependent variable. For each of the subsets we estimate a zeroinflated Poisson model. The models are defined as above except that we drop the incumbent dummy and interaction terms as explanatory variables as these make no sense for split samples.

Table 4 reports the regression results for the split sample regressions, only for challengers' reactions in Model (3) and only incumbents' reactions in Model (4). As before the upper (lower) panel reports the result of the Poisson (inflation) model, and the marginal effects for Models (3) and (4) are reported in columns $\mathrm{ME}(3)$ and $\mathrm{ME}(4)$, respectively.

\section{INSERT TABLE 4 AROUND HERE}

The results in Table 4 shed light on the counterintuitive negative coefficient in the main model. In ME(4) we see that for incumbents the effects are consistent with both Hypothesis 1 and Hypothesis 3: Incumbents' action magnitude is positively influenced by previous incumbent actions (the marginal effect of incumbent actions is positive and significant) and there is no significant effect of previous challenger moves on incumbent action magnitude.

For challengers' action magnitude the results are slightly different: The results in column $\mathrm{ME}(3)$ indicate that challengers' action magnitude is significantly positively related to previous moves by challengers (coefficient positive and significant), but negatively related to previous moves by incumbents (coefficient negative and significant). These results suggest the data supports our main proposition that action magnitude is influenced by previous rival actions, but it seems that there is an additional effect at work: the more incumbent actions observed by challengers, the smaller their action magnitude. We interpret this as challengers adopting a waitand-see strategy in our empirical setting: when there is a lot of incumbent action they reduce their activity. This also provides additional support for the intuition in $\mathrm{H} 2$ and $\mathrm{H} 3$ that strategic groups matter for competitive reactions to multiple rivals.

\section{Robustness Tests}

We report a number of robustness test including tests for multicollinearity, inclusion of incumbent tariffs on the same network, and alternative model specifications. 
Multicollinearity. Although the correlations between the independent variables reported in Table 2 are mild, the firm fixed-effects are highly correlated with the dummy variable $I n c_{i}$ by construction: each firm is either an incumbent or a challenger. This induces high multicollinearity when firm fixed effects are included. Dropping the firm fixed effects in Model (4) does not change our results but does significantly reduce multicollinearity, resulting in variance inflation factors below 2.39 and a condition number for the covariance matrix of 10.24. The results are also robust to randomly dropping $5 \%$ of the observations. Together, these tests indicate that multicollinearity is not a major concern (Belsley et al., 1980).

Incumbent tariffs on same network. The second robustness test checks that excluding incumbent tariffs introduced on the same network does not bias our results. Including the incumbent tariffs introduced on the same network in the models does not substantially change our results: In Model (4) the results are identical in sign and significance.

Alternative model specifications. To ensure our results in Model (4) are not due to specifics of the zero-inflated Poisson model we check our results against several alternative model specifications, including negative binomial, standard Poisson, and OLS specifications.

First, although the dependent variable is limited to positive integers we check our results against a simple OLS regression. The results are unchanged, except that the coefficient for $I n c_{i} \times C A_{i j t-\tau}$ is no longer significantly different from zero. Dropping the many zero observations for the OLS model does not change this result. Using an OLS model for the split samples including zero observations also does not change the results.

Second, our results are robust to using a negative binomial model or a standard Poisson model. For the full sample using the two models the marginal effects are identical except that the confidence level for the $I n c_{i} \times C A_{i j t-\tau}$ coefficient is slightly above $10 \%(\mathrm{p}<0.107$ for the negative binomial and $\mathrm{p}<0.121$ for the Poisson), whereas the coefficient for $I n c_{i} \times I A_{i j t-\tau}$ is significant at the $1 \%$ level in both models. The results of the split sample models are fully robust to using either a negative binomial or a standard Poisson model.

Third, we control for the potential influence of market entry and exit by challengers (the group of incumbents remains stable throughout). We do so by running a Poisson regression of 
challengers' actions $C A_{i j t-\tau}$ on the number of challengers in the market and using the residuals instead of $C A_{i j t-\tau}$ in Model (2). The results remain unchanged, except that the marginal effect for incumbent actions $I A_{i j t-\tau}$ is no longer significantly different from zero $(\mathrm{p}<0.142)$.

\section{DISCUSSION}

Competitive dynamics research has studied the exchange of competitive actions and responses between rival firms by focusing on action-reaction dyads (Smith et al., 2001; Hutzschenreuter and Israel, 2009). This has allowed researchers to study how firms react to specific actions by individual rivals (Chen and Miller 1994), but not on how firms react to their competitors as a group. Our study provides an early step to closing this gap by examining how firms react to multiple rival actions. Based on the awareness-motivation-capability framework we develop the concept of competitive pressure to describe the mechanism by which firms perceive and respond to actions by one or several rivals. We use strategic group theory to predict that firms react more strongly to their strategic equals, which we feel is an important nuance to our work: Firms may not react just to individual firms, but they are unlikely to consider all market participants equally important. Instead, they react to moves within their strategic group.

We first propose that firms observing more rival actions make larger competitive moves due to increased competitive pressure. Our empirical findings are consistent with this: we find evidence that firms' action magnitude is positively influenced by previous actions by rivals from their own strategic group. This suggests that firms do react to multiple rivals as a group, supporting our main argument. A surprising result that runs contrary to our expectations is that challengers' action magnitude is negatively influenced by previous incumbent actions. We attribute this to a wait-and-see strategy.

We then examine the moderating influence of strategic group on competitive pressure. We argue that managers experience greater competitive pressure when they observe actions by competitors that are similar to themselves (Chen, 1996; Young et al., 2000; Chen et al., 2007), and that this manifests itself in greater action magnitude. The data also supports this prediction: Challengers' action magnitude is influenced more strongly by the number of challengers' actions than by the number of incumbents' actions, and vice versa. This suggests that strategic groups do matter in firms' perception of competitive moves by groups of rivals. 
Our study contributes to competitive dynamics research by investigating the previously neglected question of how firms respond to actions by multiple competitors (the only exception being Hsieh and Chen, 2010). The concept of competitive pressure allows us to relax the strong assumptions implicit in the action-reaction dyad. It also lets us generalize the promising concept of competitive tension between two firms to the relationship between a firm and multiple rivals (Chen et al., 2007). It is broadly supported by the data and thus provides additional support for a perspective of competitive dynamics founded in managerial perception (Marcel et al., 2011).

Our research is related to a recent study by Hsieh and Chen (2010) that investigates the relationship between a firm and multiple rivals. We extend and complement their study in two ways. First, we propose and discuss the mechanism of competitive pressure to explain why firms take competitive action in response to multiple rivals' actions. Second, we offer a different perspective on rival actions: whereas Hsieh and Chen follow the classical literature in using a 'flow' measure of rival activity we focus on the buildup of competitive pressure by using a 'stock' measure of competitive actions.

\section{Managerial Implications}

Our results have several implications for managers deciding on strategic moves in competitive environments. First, they suggest that it may be worthwhile to monitor rival firms even if they have been inactive for some time. If an inactive rival firm observes a large number actions accumulating in the market, its competitive pressure is likely to grow, leading to a large action. Knowing what has happened in the market since a rival's last competitive move can alert managers to a potential major move in the future.

Second, when planning actions managers should screen rivals that are strategically similar to their own firm with particular care, as it is they who are most likely to respond.

Finally, firms have been shown to benefit from small, late or missing reactions to their competitive moves (Chen and MacMillan, 1992; Smith et al., 2001). Our findings suggest that to minimize rivals' reactions firms should not draw undue attention to its own and others' actions. The likely efficacy of this strategy will depend on the level of market transparency however. 


\section{Limitations and Future Directions}

Our study has several limitations. First, we do not directly observe competitive pressure using archival data. Future research would benefit from directly measuring managers' perception of actions by multiple rivals in the market, similar to recent studies on perception of pairs of rivals (Chen et al., 2007; Marcel et al., 2011; Kilduff et al., 2010). This might also allow researchers to investigate the relative importance for competitive pressure of individual rivals' actions as compared to the sum of multiple rivals' actions.

Second, we used a simple dichotomous distinction between incumbents and challengers to identify strategic groups. Future research may benefit from using more fine-grained measures to identify strategic group membership (Hatten and Hatten, 1987). We also studied only one type of action, tariff setting, and only action magnitude as an important attribute of competitive moves. While tariff setting is the most important competitive action in mobile telephony, future research using other strategic variables (e.g. advertising) may give a more complete view of competitive action in this industry. Finally, we could not explicitly link firm behavior to performance.

As discussed we used a 'stock' measure of rival actions in contrast to the common 'flow' measures of rival activity. Comparing the relative effects of stock and flow measures of rival activity on competitive pressure and firm behavior may be an interesting avenue for future work.

In summary, our study is an early attempt to extend our understanding of competitive behavior by relaxing the assumptions underlying the action-reaction dyad. We hope that future work will extend these results to advance our understanding of rivalry between multiple firms. 


\section{REFERENCES}

Barnett WP, Sorenson O. 2002. The Red Queen in Organizational Creation and Development. Industrial and Corporate Change 11(2): 289-325.

Barney JB, Hoskisson RE. 1990. Strategic Groups: Untested Assertions and Research Proposals. Managerial and Decision Economics 11: 187-98.

Belsley DA, Kuh E, Welsch RE. 1980. Regression Diagnostics: Identifying Influential Data and Sources of Colliearity. John Wiley \& Sons: New York.

Bettis RA, Weeks D. 1987. Financial Returns and Strategic Interaction: The Case of Instant Photography. Strategic Management Journal 8: 549-63.

Bothner MS, Kang J, Stuart TE. 2007. Competitive Crowding and Risk Taking in a Tournament: Evidence from NASCAR Racing. Administrative Science Quarterly 52: 20847.

Chen MJ. 1996. Competitor Analysis and Interfirm Rivalry: Towards A Theoretical Integration. Academy of Management Review 21(1): 100-34.

Chen MJ, Hambrick DC. 1995. Speed, Stealth, and Selective Attack: How Small Firms Differ from Large Firms in Competitive Behavior. Academy of Management Journal 38(2): 453-82.

Chen MJ, MacMillan I. 1992. Nonresponse and Delayed Response to Competitive Moves: The Roles of Competitor Dependence and Action Irreversibility. Academy of Management Journal 35(3): 539-70.

Chen MJ, Miller D. 1994. Competitive Attack, Retaliation and Performance: An ExpectancyValence Framework. Strategic Management Journal 15: 85-102.

Chen MJ, Smith KG, Grimm CM. 1992. Action Characteristics as Predictors of Competitive Responses. Management Science 38(3): 439-55.

Chen MJ, Su K, Tsai W. 2007. Competitive Tension: The Awareness-Motivation-Capability Perspective. Academy of Management Journal 50(1): 101-18.

Cool KO, Dierickx I. 1993. Rivalry, Strategic Groups and Firm Profitability. Strategic Management Journal 14: 47-59.

Fernández Z, Usero B. 2009. Competitive Behavior in the European Mobile Telecommunications Industry: Pioneers vs. Followers. Telecommunications Policy 33: 33947. 
Ferrier WJ. 2001. Navigating the Competitive Landscape: The Drivers and Consequences of Competitive Aggressiveness. Academy of Management Journal 44(4): 858-77.

Ferrier WJ, Lee H. 2002. Strategic Aggressiveness, Variation, And Surprise: How The Sequential Pattern Of Competitive Rivalry Influences Stock Market Returns. Journal of Managerial Issues 14(2): 162-80.

Ferrier WJ, Mac Fhionnlaoich C, Smith KG, Grimm CM. 2002. The Impact of Performance Distress on Aggressive Competitive Behavior: A Reconciliation of Conflicting Views. Managerial and Decision Economics 23: 301-16.

Ferrier WJ, Smith KG, Grimm CM. 1999. The Role of Competitive Action in Market Share Erosion and Industry Dynamics: A Study of Industry Leaders and Challengers. Academy of Management Journal 42(4): 372-88.

Fjeldstad OD, Becerra M, Narayanan S. 2004. Strategic Action in Network Industries: An Empirical Analysis of the European Mobile Phone Industry. Scandinavian Journal of Management 20: 173-96.

German Federal Network Agency. 2009. Jahresbericht 2009: Annual Report of the German Federal Network Agency [16 March 2011].

German Federal Statistical Agency. 2006. Recalculating the Consumer Price Index for Telecommunications Services on Base 2000: Methodological Description. http://www.destatis.de/ [16 March 2011].

Greve HR. 2003. A Behavioral Theory of R\&D Expenditures and Innovations: Evidence from Shipbuilding. The Academy of Management Journal 46(6): 685-702.

Grzybowski L, Pereira P. 2008. The Complementarity Between Calls and Messages in Mobile Telephony. Information Economics and Policy 20(3): 279-87.

Hatten K, Hatten ML. 1987. Strategic Groups, Asymmetrical Mobility Barriers and Contestability. Strategic Management Journal 8: 329-42.

Hoetker G. 2007. The use of logit and probit models in strategic management research: Critical issues. Strategic Management Journal 28(4): 331-43.

Hseih K, Chen M. 2010. Responding to Rivals' Actions: Beyond Dyadic Conceptualization of Interfirm Rivalry. Working Paper presented at the Academy of Management Annual Conference 2010. 
Hutzschenreuter T, Israel S. 2009. A Review of Empirical Research on Dynamic Competitive Strategy. International Journal of Management Reviews 11(4): 421-61.

Keil T, Maula M, Schildt H, Zahra SA. 2008. The Effect of Governance Modes and Relatedness of External Business Development Activities on Innovative Performance. Strategic Management Journal 29(8): 895-907.

Ketchen DJ, JR., Shook CL. 1996. The Application of Cluster Analysis in Strategic Management Research: An Analysis and Critique. Strategic Management Journal 17: 441-58.

Ketchen DJ, JR., Snow CC, Hoover VL. 2004. Research on Competitive Dynamics: Recent Accomplishments and Future Challenges. Journal of Management 30(6): 779-804.

Kilduff GJ, Elfenbein HA, Staw BM. 2010. The Psychology of Rivalry: A Relationally Dependent Analysis of Competition. Academy of Management Journal 53(5): 943-69.

Lambert D. 1992. Zero-Inflated Poisson Regression, with an Application to Defects in Manufacturing. Technometrics 34(1): 1-14.

Leask G, Parker D. 2007. Strategic Groups, Competitive Groups and Performance Within the U.K. Pharmaceutical Industry: Improving Our Understanding of the Competitive Process. Strategic Management Journal 28: 723-45.

Li J. 2008 Asymmetric Interactions between Foreign and Domestic Banks: Effects on Market Entry. Strategic Management Journal 29(8): 873-93.

Livengood RS, Reger RK. 2010. That's Our Turf! Identity Domains and Competitive Dynamics. Academy of Management Review 35(1): 48-66.

Marcel JJ, Barr PS, Duhaime IM. 2011. The Influence of Executive Cognition on Competitive Dynamics. Strategic Management Journal 32(2): 115-38.

Más-Ruiz FJ, Nicolau-Gonzálbez JL, Ruiz-Moreno F. 2005. Asymmetric Rivalry Between Strategic Groups: Response, Speed of Response and Ex-Ante vs. Ex-Post Competitive Interaction in the Spanish Banking Market. Strategic Management Journal 26: 713-45.

McGee J, Thomas H. 1986. Strategic Groups: Theory, Research and Taxonomy. Strategic Management Journal 7: 141-60.

Miravete EJ. 2009. Competing with Menus of Tariff Options. Journal of the European Economic Association 7(1): 188-205.

Nath D, Gruca TS. 1997. Convergence Across Alternative Methods for Forming Strategic Groups. Strategic Management Journal 18(9): 745-60. 
Norton EC, Wang H, Ai C. 2004. Computing Interaction Effects and Standard Errors in Logit and Probit Models. The Stata Journal 4(2): 154-67.

Peteraf M, Shanley M. 1997. Getting to Know You: A Theory of Strategic Group Identity. Strategic Management Journal 18: 165-86.

Porac JF, Thomas H. 1990. Taxonomic Mental Models in Competitor Definition. The Academy of Management Review 15(2): 224-40.

Porac JF, Thomas H. 1994. Cognitive Categorization and Subjective Rivalry Among Retailers in a Small City. Journal of Applied Psychology 79(1): 54-66.

Porac JF, Thomas H, Baden-Fuller C. 1989. Competitive Groups as Cognitive Communities: The Case of Scottish Knitwear Manufacturers. Journal of Management Studies 26(4): 397-416.

Porac JF, Thomas H, Wilson F, Paton D, Kanfer A. 1995. Rivalry and the Industry Model of Scottish Knitwear Producers. Administrative Science Quarterly 40(2): 203-27.

Porter ME. 1979. The Structure within Industries and Companies' Performance. Review of Economics and Statistics 61(2): 214-27.

Porter ME. 1980. Competitive Strategy. The Free Press: New York.

Reger RK, Huff AS. 1993. Strategic Groups: A Cognitive Perspective. Strategic Management Journal 14(2): 103-23.

Smith KG, Ferrier WJ, Ndofor H. 2001. Competitive Dynamics Research: Critique and Future Directions. In The Blackwell Handbook of Strategic Management, Hitt MA, Freeman RE, Harrison JS (eds). Blackwell Publishing: Oxford; 314-361.

Smith KG, Grimm CM, Gannon MJ. 1992. Dynamics of Competitive Strategy. SAGE Publications: Newbury Park, CA.

Smith KG, Grimm CM, Gannon MJ, Chen M. 1991. Organizational Information Processing, Competitive Responses, and Performance in the U.S. Domestic Airline Industry. The Academy of Management Journal 34(1): 60-85.

Smith KG, Grimm CM, Wally S, Young G. 1997. Strategic Groups and Rivalrous Firm Behavior: Towards a Reconciliation. Strategic Management Journal 18(2): 149-57.

Tang M, Thomas H. 1992. The Concept of Strategic Groups: Theoretical Construct or Analytical Convenience. Managerial and Decision Economics 13: 323.329.

Winkelmann R. 2003. Econometric Analysis of Count Data. 4th ed. Springer: Berlin et al. 
Young G, Smith KG, Grimm CM. 1996. "Austrian" and Industrial Organization Perspectives on Firm-Level Competitive Activity and Performance. Organization Science 7(3): 243-54.

Young G, Smith KG, Simon D. 2000. Multimarket Contact and Resource Dissimilarity: A Competitive Dynamics Perspective. Journal of Management 26(6): 1217-36.

Yu T, Cannella AA. 2007. Rivalry Between Multinational Enterprises: An Event History Approach. Academy of Management Journal 50(3): 663-84.

Zelner B. 2009. Using Simulation to Interpret Results from Logit, Probit, and Other Nonlinear Models. Strategic Management Journal 30(12): 1335-1348. 


\section{APPENDIX A - MAIN TABLES AND FIGURES}

Figure 1: Proposed Relationships

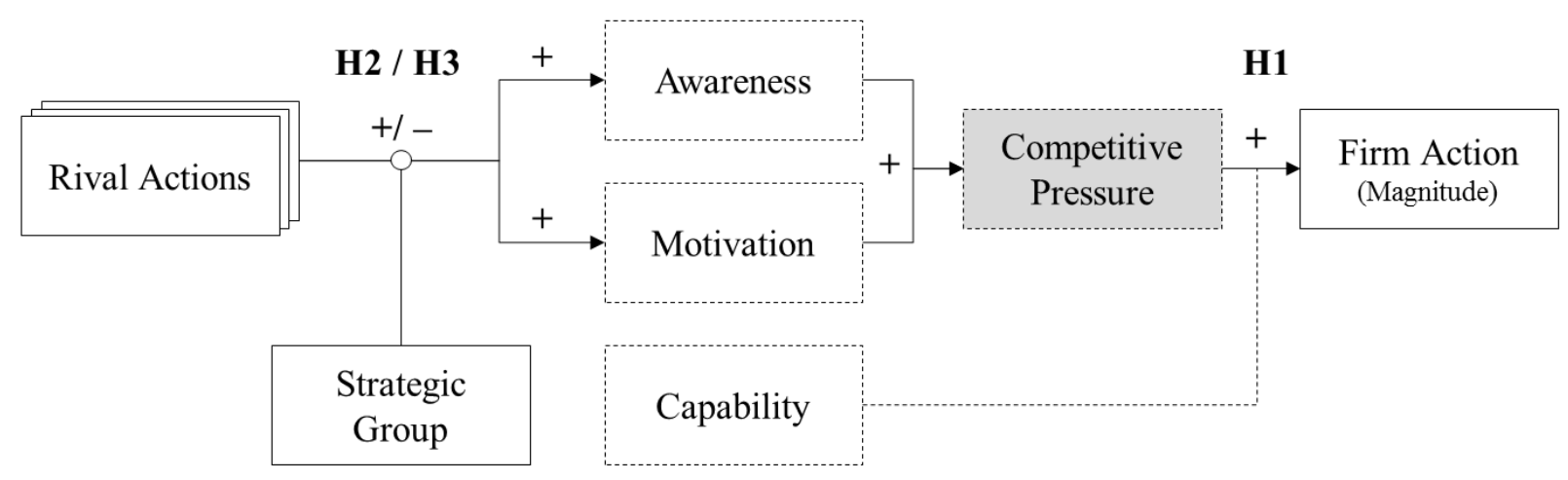




\section{Table 1: Descriptive Statistics}

\begin{tabular}{|c|c|c|c|c|c|}
\hline \multicolumn{2}{|c|}{ Variable } & \multirow{2}{*}{$\begin{array}{r}\text { Mean } \\
0.39\end{array}$} & \multirow{2}{*}{$\begin{array}{l}\text { SD } \\
1.48\end{array}$} & \multirow{2}{*}{$\begin{array}{l}\text { Min } \\
\\
\end{array}$} & \multirow{2}{*}{$\begin{array}{r}\text { Max } \\
18\end{array}$} \\
\hline (1) & Action Magnitude & & & & \\
\hline (2) & Challengers' Actions (CA) & 13.42 & 14.93 & 0 & 112 \\
\hline (3) & Incumbents' Actions (IA) & 13.75 & 21.33 & 0 & 187 \\
\hline (4) & Incumbent (dummy) & 0.34 & - & 0 & 1 \\
\hline (5) & Incumbent $\mathrm{x} C \mathrm{CA}$ & 2.48 & 7.19 & 0 & 67 \\
\hline \multirow[t]{2}{*}{ (6) } & Incumbent x IA & 2.93 & 7.25 & 0 & 67 \\
\hline & & 2105 & & & \\
\hline
\end{tabular}

Table 2: Correlation Table

\begin{tabular}{clccccc}
\hline Variable & & $(\mathbf{1})$ & $\mathbf{( 2 )}$ & $\mathbf{( 3 )}$ & (4) & (5) \\
\hline$(1)$ & Action Magnitude & 1 & & & & \\
$(2)$ & Challengers' Actions (CA) & $-0.063^{*}$ & 1 & & & \\
$(3)$ & Incumbents' Actions (IA) & -0.007 & $0.559^{*}$ & 1 & & \\
$(4)$ & Incumbent (dummy) & $0.227^{*}$ & $-0.298^{*}$ & $-0.176^{*}$ & 1 & \\
$(5)$ & Incumbent x CA & $0.122^{*}$ & $0.229^{*}$ & -0.010 & $0.479^{*}$ & 1 \\
$(6)$ & Incumbent x IA & $0.259^{*}$ & $-0.062^{*}$ & $0.135^{*}$ & $0.560^{*}$ & $0.486^{*}$ \\
\hline & & 2105 & & & & \\
\hline
\end{tabular}

Asterisks mark correlations that are significantly different from zero at the 5\% level 
Table 3: Full Sample Regression Models

\begin{tabular}{|c|c|c|c|c|}
\hline \multirow[t]{2}{*}{ Action Magnitude } & \multicolumn{2}{|c|}{ Regression Coefficients } & \multicolumn{2}{|c|}{ Marginal Effects } \\
\hline & (1) & (2) & (ME1) & (ME2) \\
\hline \multicolumn{5}{|l|}{ Conditional Poisson Model } \\
\hline Challengers' Actions (CA) & $\begin{array}{l}-0.006 \\
(0.006)\end{array}$ & $\begin{array}{c}0.032 * * * \\
(0.011)\end{array}$ & $\begin{array}{c}0.007 * * \\
(0.003)\end{array}$ & $\begin{array}{c}0.010 * * \\
(0.004)\end{array}$ \\
\hline Incumbents' Actions (IA) & $\begin{array}{c}-0.013 * * * \\
(0.004)\end{array}$ & $\begin{array}{c}-0.023 * * \\
(0.008)\end{array}$ & $\begin{array}{l}0.004 * \\
(0.003)\end{array}$ & $\begin{array}{c}-0.010 * * * \\
(0.003)\end{array}$ \\
\hline Incumbent & $\begin{array}{c}3.800 * * * \\
(1.431)\end{array}$ & $\begin{array}{c}1.680 \\
(1.989)\end{array}$ & $\begin{array}{c}0.776 \\
(0.975)\end{array}$ & $\begin{array}{c}0.531 \\
(0.543)\end{array}$ \\
\hline Incumbent $\mathrm{x} C \mathrm{CA}$ & & $\begin{array}{c}-0.041 \text { *** } \\
(0.012)\end{array}$ & & $\begin{array}{c}-0.016^{* * *} \\
(0.005)\end{array}$ \\
\hline Incumbent x IA & & $\begin{array}{c}0.018 * * \\
(0.009)\end{array}$ & & $\begin{array}{c}0.007 * \\
(0.004)\end{array}$ \\
\hline Constant & $\begin{array}{l}-2.093 \\
(1.455) \\
\end{array}$ & $\begin{array}{c}-0.136 \\
(2.015) \\
\end{array}$ & & \\
\hline \multicolumn{5}{|l|}{ Inflation Model } \\
\hline Challengers' Actions (CA) & $\begin{array}{c}-0.040 * * \\
(0.017)\end{array}$ & $\begin{array}{c}0.011 \\
(0.019)\end{array}$ & & \\
\hline Incumbents' Actions (IA) & $\begin{array}{c}-0.039 * * * \\
(0.011)\end{array}$ & $\begin{array}{c}0.002 \\
(0.014)\end{array}$ & & \\
\hline Incumbent & $\begin{array}{c}2.892 \\
(5.304)\end{array}$ & $\begin{array}{c}0.500 \\
(1.732)\end{array}$ & & \\
\hline Incumbent $\mathrm{x} C \mathrm{CA}$ & & $\begin{array}{c}-0.036 \\
(0.024)\end{array}$ & & \\
\hline Incumbent x IA & & $\begin{array}{c}-0.064 * * * \\
(0.017)\end{array}$ & & \\
\hline Constant & $\begin{array}{c}0.899 \\
(5.338)\end{array}$ & $\begin{array}{l}-1.483 \\
(0.790)\end{array}$ & & \\
\hline \multicolumn{5}{|l|}{ Fixed Effects } \\
\hline Firms & yes & yes & & \\
\hline Markets & yes & yes & & \\
\hline Years & yes & yes & & \\
\hline Seasons (months) & yes & yes & & \\
\hline Observations & 2,105 & 2,105 & & \\
\hline Chi-squared statistic & 556.9 & 536.21 & & \\
\hline Model test (Chi-squared) & 0.000 & 0.000 & & \\
\hline
\end{tabular}


Table 4: Split Sample Regression Models

Action Magnitude

\begin{tabular}{|c|c|c|c|c|}
\hline & $\begin{array}{c}\text { Challengers } \\
\text { (3) }\end{array}$ & $\begin{array}{c}\text { Incumbents } \\
\text { (4) }\end{array}$ & $\begin{array}{c}\text { Marginal } \\
\text { Effects } \\
\text { Challengers } \\
\text { (ME3) }\end{array}$ & $\begin{array}{c}\text { Marginal } \\
\text { Effects } \\
\text { Incumbents } \\
\text { (ME4) }\end{array}$ \\
\hline \multicolumn{5}{|l|}{ Conditional Poisson Model } \\
\hline Challengers' Actions (CA) & $\begin{array}{c}0.003 \\
(0.011)\end{array}$ & $\begin{array}{l}-0.006 \\
(0.008)\end{array}$ & $\begin{array}{c}0.005^{* * *} \\
(0.002)\end{array}$ & $\begin{array}{c}0.011 \\
(0.013)\end{array}$ \\
\hline Incumbents' Actions (IA) & $\begin{array}{l}-0.006 \\
(0.010)\end{array}$ & $\begin{array}{l}-0.003 \\
(0.005)\end{array}$ & $\begin{array}{c}-0.005^{* * *} * \\
(0.001)\end{array}$ & $\begin{array}{c}0.027 * * * \\
(0.007)\end{array}$ \\
\hline Constant & $\begin{array}{c}0.414 \\
(0.721)\end{array}$ & $\begin{array}{c}1.200 * * \\
(0.328)\end{array}$ & & \\
\hline \multicolumn{5}{|l|}{ Inflation Model } \\
\hline Challengers' Actions (CA) & $\begin{array}{c}-0.073 * * * \\
(0.022)\end{array}$ & $\begin{array}{l}-0.028 \\
(0.026)\end{array}$ & & \\
\hline Incumbents' Actions (IA) & $\begin{array}{c}0.056 * * \\
(0.026)\end{array}$ & $\begin{array}{c}-0.050 * * * \\
(0.012)\end{array}$ & & \\
\hline Constant & $\begin{array}{c}-10.604 \\
(563.7)\end{array}$ & $\begin{array}{c}1.396 * * * \\
(0.523)\end{array}$ & & \\
\hline \multicolumn{5}{|l|}{ Fixed Effects } \\
\hline Firms & no & no & & \\
\hline Markets & yes & yes & & \\
\hline Years & yes & yes & & \\
\hline Seasons (months) & yes & no & & \\
\hline Observations & 1,385 & 720 & & \\
\hline Chi-squared statistic & 121.41 & 185.02 & & \\
\hline Model test (Chi-squared) & 0.000 & 0.000 & & \\
\hline
\end{tabular}

Robust standard errors in parentheses

$* * * \mathrm{p}<0.01, * * \mathrm{p}<0.05, * \mathrm{p}<0.1$ 


\section{APPENDIX B - SUPPLEMENTARY MATERIAL}

\section{Allocation of Tariffs to Markets}

Initially, the dataset lacked a segmentation of the tariff market although tariffs were obviously targeted at different consumer segments, e.g. occasional callers and heavy usage business consumers. Treating all tariffs as competing equally for the same consumers would skew our results, so we allocated each tariff to a unique market segment (subsequently referred to simply as 'market'). This is achieved using three standard usage baskets defined by the German Federal Statistical Agency (2006) for 'rare', 'low' and 'average' cellular phone users. No basket was available for business users, so we defined a 'heavy' user basket as an inflated version of the average user basket. The baskets are provided in Table B1.

Each tariff was allocated to a unique basket ('market') with the following procedure:

1. Calculate the monthly cost of each tariff for each of the four user baskets using the tariff components and the usage pattern for the baskets.

2. Using all tariffs, identify the lower 10\%-ile in terms of cost for each user basket by month.

3. Calculate the relative distance of each tariff's cost to the lower cost percentile for each user basket in the month it was introduced.

4. Allocate each tariff to the basket where the relative distance is smallest.

In calculating the monthly cost we make two simplifying assumptions. First, we take assume calls are distributed evenly over the day. In the period covered by our dataset a decreasing number of tariffs differentiate between different times of day ; where different rates were offered we used the average cost. Second, if off-net prices varied for different providers we used the average off-net price. This affected only a minor percentage of the tariffs in the sample.

The results of the tariff allocation for average monthly user bills are provided in Table B2. A potential weakness of the market allocation procedure is that the user baskets were only available for 2000. In the time between then and the end of our dataset there may have been changes in usage patterns arising endogenously from increasing diffusion and falling prices. 
The allocation was robust towards a wide range of inflation factors for the heavy user basket and towards using fiscal quarters rather than months to define the lower cost quartile. Results were also robust towards using lower percentiles between 5\% and $15 \%$. The $10 \%$-ile level was chosen because it yielded the most plausible allocation based on a qualitative investigation of tariff names. The lists allocating the tariffs to the markets are available on request from the authors.

\section{Table B1: Tariff Allocation}

\section{Results of Tariff Allocation to Markets}

Observations and average monthly user bill in EUR

\begin{tabular}{lrrrrr}
\hline Market & Obs. & Mean* & \multicolumn{1}{l}{ SD* } & Min* & Max* \\
\hline Rare & 162 & 8.89 & 4.66 & 2.00 & 24.54 \\
Low & 163 & 36.61 & 8.26 & 15.45 & 56.00 \\
Average & 173 & 56.80 & 15.42 & 26.00 & 102.73 \\
Heavy & 321 & 126.05 & 45.43 & 9.00 & 308.25 \\
\hline
\end{tabular}

* Units = EUR / month 


\section{Table B2: Usage baskets}

\section{Usage in minutes}

(monthly values calculated on basis of German Federal Network Authority's baskets of 2000)

Assumption: Call duration constant over different types

\begin{tabular}{ccccccr} 
& Unit & & $\begin{array}{c}\text { Rare } \\
\text { users }\end{array}$ & & $\begin{array}{c}\text { Low-level } \\
\text { users }\end{array}$ & \multicolumn{2}{c}{$\begin{array}{c}\text { Average } \\
\text { users }\end{array}$} & Heavy users* \\
\hline Total duration of calls & $\min$ & 20 & 60 & 200 & 600 \\
o/w to own network & $\min$ & 7 & 27 & 69 & 207 \\
o/w to other network & $\min$ & 4 & 9 & 40 & 120 \\
o/w to fixed-line & $\min$ & 9 & 24 & 91 & 273 \\
\hline SMS & $\#$ & 20 & 60 & 60 & 180 \\
\hline
\end{tabular}

* Note: No basket was available for heavy users, therefore two assumptions were made:

- Call distribution is assumed to be identical to average users.

- Total call duration is assumed to be 600 min (30min x 20 working days) 


\section{Data Cleaning}

The data gathered by Teltarif was subjected to extensive cleaning at the provider and tariff levels.

Providers. Non-mobile operators, e.g. a data-service company offering tariffs as an add-on for companies implementing software solutions were excluded from the dataset. Furthermore, 22 providers which each introduced only a single tariff in one month and market were dropped for the calculation of the dependent variable, as these tariff introductions cannot seriously be considered reactions. Three providers who had only a few tariffs and for whom no information could be found on the internet were also dropped from the dataset. Finally, seventeen tariff resellers were dropped, as discussed in detail in the paper.

Tariffs. The following tariffs were dropped to avoid distortions in price calculations and the calculated number of new tariffs: Bundles including a mobile tariff and DSL (broadband) access, bundles including a mobile tariff and a fixed-line tariff, add-on options for tariffs (such as 'Extra 100 free SMS'), and pure data tariffs for mobile devices (without calling functionality),

Note that tariffs are also influenced by firms' strategy of attracting new consumers by subsidizing mobile handsets, and subsequently recovering their investment over the duration of the tariff contract. While we cannot control for this effect due to a lack of data on handset subsidies, we argue that a new tariff constructed to subsidize a particular handset does constitute a competitive move. 